Article

\title{
Confirmation of Initial Stable Adsorption Structures of Leucine and Tyrosine Adsorbed on a Cu(110) Surface
}

\author{
Hangil Lee ${ }^{1}$ and Hyun Sung Kim ${ }^{2, *}$ \\ 1 Department of Chemistry, Sookmyung Women's University, Seoul 04310, Korea; easyscan@sookmyung.ac.kr \\ 2 Department of Chemistry, Pukyong National University, Busan 48513, Korea \\ * Correspondence: kimhs75@pknu.ac.kr; Tel.: +82-51-629-5596
}

Received: 17 January 2020; Accepted: 11 February 2020; Published: 14 February 2020

\begin{abstract}
The structures and stability levels of leucine (Leu) and tyrosine (Tyr) adsorbed on a $\mathrm{Cu}(110)$ surface, at initial levels of coverage (less than 0.25 monolayer), were investigated using reflection-absorption infrared spectroscopy and high-resolution photoemission spectroscopy (HRPES), as well as by performing density functional theory calculations. At an initial coverage, the $\mathrm{O}-\mathrm{H}$ dissociation bonded structure was indicated from the spectral results to be the most favorable structure for Leu adsorbed on the $\mathrm{Cu}(110)$ surface, whereas the $\mathrm{O}-\mathrm{H}$ dissociated-N dative bonded structure was most favorable for adsorbed Tyr. These models were further supported by the results of experiments, in which the systems were exposed to other molecules and HRPES was used to monitor whether the amine or carboxylic groups of the adsorbed amino acids became reactive.
\end{abstract}

Keywords: adsorption structure; amino acids; HRPES; RAIRS; DFT

\section{Introduction}

In the field of surface science, research on the interactions between biomolecules, including their various functional groups $\left(-\mathrm{NH}_{2},-\mathrm{COOH},-\mathrm{OH}\right.$, and $\left.-\mathrm{SH}\right)$, and substrates is focused on determining which structure is the most stable adsorption structure during initial coverage because these structures are important for practical applications, such as biosensors and bio-selective chips [1-7]. Notably, the adsorption structures of amino acids have yielded versatile applications because they include various functional groups, all containing a carboxyl group $(-\mathrm{COOH})$ and an amino group $\left(-\mathrm{NH}_{2}\right)[8,9]$. Previous studies of high-resolution photoemission spectroscopy (HRPES) and scanning tunneling microscopy (STM), as well as the density functional theory (DFT), have noted that the O-H dissociated-N dative bonded structure (with the carboxylate oxygen atoms and the nitrogen atom participating in the adsorption) and $\mathrm{O}-\mathrm{H}$ dissociation bonded structure (with only the carboxylate oxygen atoms participating in the adsorption) are generally the stable adsorption features for amino acids on a $\mathrm{Ge}(100)$ surface, depending on the their adsorbed coverages [10-13].

To determine how adsorption structures depend on the substrate (semiconductor or metal), the adsorption structures of the amino acids leucine (Leu) and tyrosine (Tyr) on a $\mathrm{Cu}(110)$ surface at initial coverage were acquired. A previous STM study revealed the $\mathrm{O}-\mathrm{H}$ dissociation bonded structure to be the most stable adsorption structure of most amino acids adsorbed on the $\mathrm{Cu}(110)$ surface [14]. As the carboxylate group has two equivalent oxygen atoms, they adsorb on the $\mathrm{Cu}(110)$ surface in two equivalent manners. For this specific purpose, a comparative investigation of the adsorption of Leu and Tyr on a $\mathrm{Cu}(110)$ surface at low coverage for clarifying the stable structure-less than 0.25 monolayer (ML) - was carried out using various surface analysis tools, such as reflection-absorption infrared spectroscopy (RAIRS), HRPES, and DFT calculations. 


\section{Materials and Methods}

The cleaning of a $\mathrm{Cu}(110)$ surface $(10 \times 10 \times 1 \mathrm{~mm})$ was carried out using several cycles of Ar+ ion sputtering at $1 \mathrm{keV}$ for $20 \mathrm{~min}$ per cycle at $700 \mathrm{~K}$, followed by an additional annealing process at $1100 \mathrm{~K}$ for $20 \mathrm{~min}$. The level of cleanliness of the $\mathrm{Cu}(110)$ surface was confirmed using low-energy electron diffraction measurements of pristine $\mathrm{Cu}(110)$ surface. L-leucine (Leu; $\mathrm{C}_{3} \mathrm{H}_{7} \mathrm{NO}_{2},<99 \%$ purity; Sigma Aldrich, St. Louis, Missouri, United States) and L-tyrosine (Tyr; $\mathrm{C}_{9} \mathrm{H}_{11} \mathrm{NO}_{3},<99 \%$ purity; Sigma Aldrich, St. Louis, Missouri, United States) were purchased and further purified by several sublimation cycles to remove contaminated impurity prior to the adsorption experiments.

RAIRS spectra were obtained using a NICOLET 6700 FT-IR spectrometer (Thermo Scientific, US), which was equipped with liquid nitrogen (LN2)-cooled MCT (Mercury-Cadmium-Telluride). All RAIR spectra of the specimen were measured at less than $1 \times 10^{-10}$ Torr, referring to a background single-beam spectrum recorded on pristine $\mathrm{Cu}(110)$ surface. Each spectrum with a spectral range of $800-3200 \mathrm{~cm}^{-1}$ was obtained at a resolution of $4 \mathrm{~cm}^{-1}$ by averaging 500 scans.

The $\mathrm{C} 1 \mathrm{~s}, \mathrm{~N}$ 1s, and $\mathrm{O} 1 \mathrm{~s}$ core-level spectra included in amino acids molecules were acquired using HRPES equipped at the Pohang Accelerator Laboratory (10D HRPES-I beamline) with photon energies of 340, 460, and $590 \mathrm{eV}$ to increase the surface sensitivity factors. Their binding energies were corrected by that of the pure $\mathrm{Au} 4 \mathrm{f}$ core-level spectrum $(84.0 \mathrm{eV})$ for the identical photon energy. The base pressure of the chamber was maintained under ultra-high vacuum condition (below $9.5 \times 10^{-11}$ Torr). The three core-level spectra were carefully fitted with Voigt functions to analyze the bonding configurations [15]. The 1.0 ML of Leu and Tyr coverage was defined as the maximum density at which they can be deposited on a $\mathrm{Cu}(110)$ surface without yielding the $\mathrm{N} 1$ s core-level peak at $399.1( \pm 0.1) \mathrm{eV}$ characteristic of multilayer formation.

DFT calculations were also performed to predict the adsorption energies of Leu and Tyr on the $\mathrm{Cu}(110)$ surface. All DFT adsorption energy was calculated by using the JAGUAR 9.1 software package, which applied a hybrid density functional method and included Becke's three-parameter nonlocal exchange functional with Lee, Yang, and Parr nonlocal correlation functional (B3LYP) [16]. In these calculations, we considered four-dimer (Cu35H32) cluster models. For the determination of the geometries corresponding to the important local minima on the potential energy surface, we applied a mixed basis set that uses the LACVP basis set to describe $\mathrm{Cu}$ atoms and the 6-31 $\mathrm{G}$ basis set to describe the remaining atoms developed by Hay and Wadt [17]. In detail, the upper layer structure of $\mathrm{Cu}$ atoms allowed the atoms of the adsorbate to relax because the adsorption proceeded directly, and the optimization energy was calculated by fixing the lower layer of $\mathrm{Cu}$ atoms. Each calculated energy value was obtained with the minimum value and the geometry was chosen. We also verified the local minimum and transition states in each calculation.

\section{Results}

The RAIR spectra of Leu were first acquired at a low coverage of $\sim 0.20 \mathrm{ML}$ on the $\mathrm{Cu}(110)$ surface at a relatively low coverage, as shown in Figure 1a. For molecules in general, their adsorption geometries can only be predicted by assigning the vibrational absorption bands associated with each of the main functional groups in the tested molecules (e.g., the $\mathrm{COO}-,-\mathrm{NH}_{2},-\mathrm{CH}_{3}$, and $-\mathrm{CH}$ - groups) as shown in Scheme 1. If all the bands in an RAIR spectrum can be analyzed to the functional groups of the molecule, then one can conclude that the molecule is adsorbed intact. 
(a)<smiles>CC(C)C[C@H](N)C(=O)O</smiles><smiles>N[C@@H](Cc1ccc(O)cc1)C(=O)O</smiles>

Scheme 1. Molecular structures of (a) leucine and (b) tyrosine.

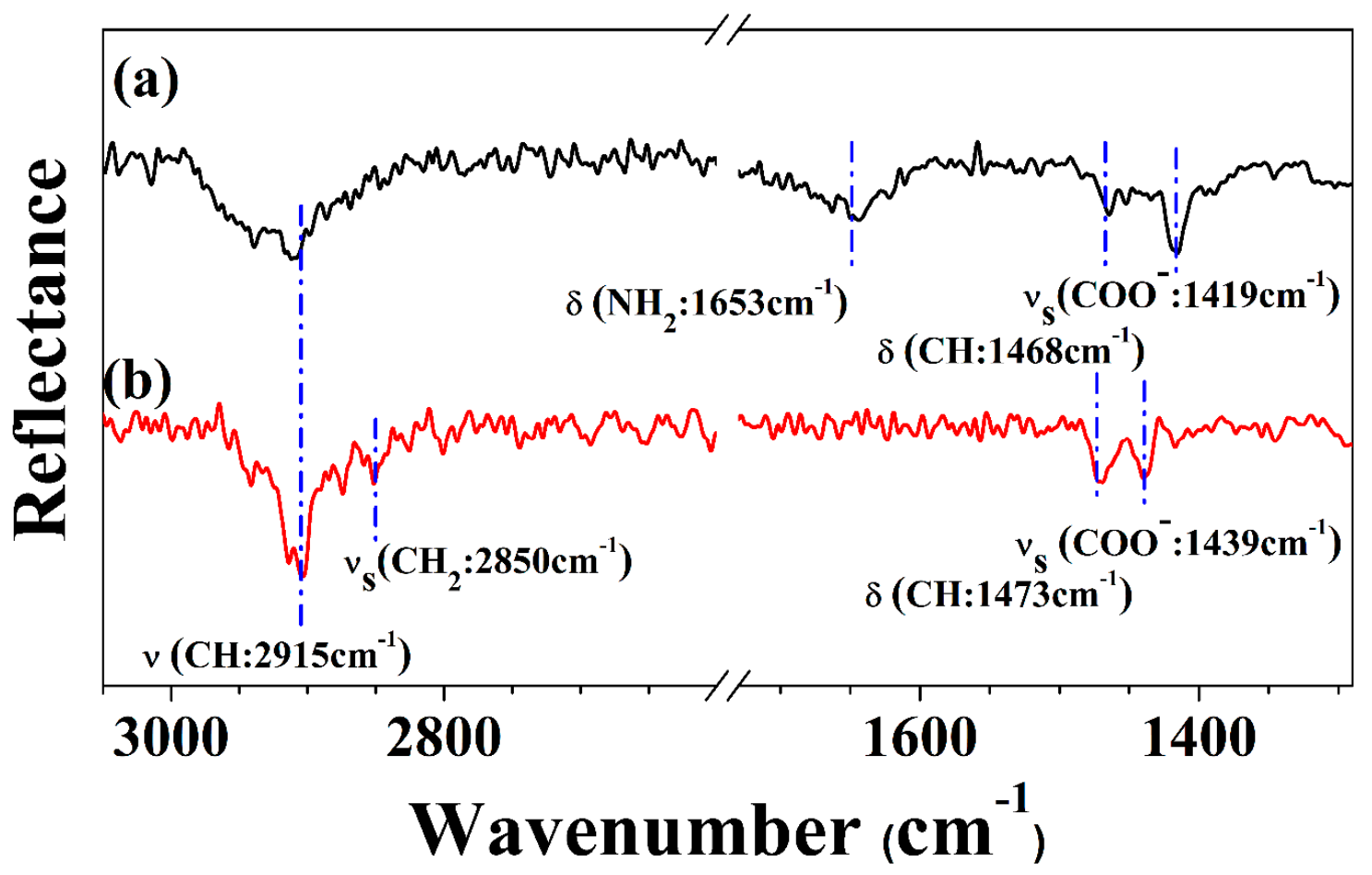

Figure 1. Reflection-absorption infrared (RAIR) spectra of (a) Leu and (b) Tyr on the $\mathrm{Cu}(110)$ surface at room temperature.

The RAIR spectrum of Leu clearly showed a band at $1653 \mathrm{~cm}^{-1}$, which was because of the asymmetric deformation mode of the $\mathrm{NH}_{2}$ group. Therefore, it is suggested that the amine group participated in the adsorption on the $\mathrm{Cu}(110)$ surface at low coverage. However, an $\mathrm{NH}_{2}{ }^{+}$peak was not observed, because the plane of the $\mathrm{NH}_{2}{ }^{+}$group was, according to previous work, lying parallel to the surface [18]. Generally, the carboxylate group will give rise to two vibrational absorption features corresponding to the asymmetric and symmetric COO- stretching modes occurring at 1620-1540 $\mathrm{cm}^{-1}$ and $1420-1300 \mathrm{~cm}^{-1}$, respectively. However, in the obtained RAIR spectrum of the $\mathrm{Cu}(110)$ surface at low coverage of Leu, only the band at $1419 \mathrm{~cm}^{-1}$ assigned to symmetric COO- stretching mode was observed. This result indicated that the two oxygen atoms in the carboxylate group are equidistant to the surface, which may be involved in the binding on the surface, resulting in making the stretch dipole of COO- to be inactive. A band at $2915 \mathrm{~cm}^{-1}$ was also observed, and it may have been caused by the $\mathrm{CH}$ stretching modes-in particular, because these groups were slightly tilted from the normal position to the $\mathrm{Cu}(110)$ surface. Taken together, these RAIRS observations could support the adoption of the $\mathrm{O}-\mathrm{H}$ dissociation bonded structure by Leu at low coverage on the $\mathrm{Cu}(110)$ surface. 
Following the same method, RAIR spectra of Tyr on the $\mathrm{Cu}(110)$ surface at low coverage were obtained, as displayed in Figure $1 \mathrm{~b}$. Here, vibrations arose from the carboxylate (COO-) and amino $\left(\mathrm{NH}_{2}\right)$ groups. However, a peak at $1592 \mathrm{~cm}^{-1}$, corresponding to the asymmetric deformation mode of the $\mathrm{NH}_{2}$ group, did not appear. Additionally, while the COO- stretching mode at $1439 \mathrm{~cm}^{-1}$ was observed, the asymmetric vas (COO-) stretch was not found, and these results are similar to those for Leu, suggesting that the two carboxylate oxygen atoms of Tyr also bound equidistantly to the $\mathrm{Cu}(110)$ surface. These differential observations taken together were consistent with the appearance of the $\mathrm{O}-\mathrm{H}$ dissociated-N dative bonded structure for Tyr at low coverage on the $\mathrm{Cu}(110)$ surface.

To determine the electronic structures of the two adsorbed amino acids and, hence, the most favorable adsorption structures, high-resolution core-level spectra were obtained for Leu and Tyr adsorbed on the $\mathrm{Cu}(110)$ surface at a low coverage of $\sim 0.20 \mathrm{ML}$ (Figure 2). Their $\mathrm{C} 1 \mathrm{~s}, \mathrm{~N} 1 \mathrm{~s}$, and $\mathrm{O} 1 \mathrm{~s}$ core-level spectra were specifically acquired and analyzed using HRPES.

Four chemically distinct types of carbon were determined to be present on the $\mathrm{Cu}(110)$ surface exposed to $\sim 0.20 \mathrm{ML}$ Leu, according to its $\mathrm{C} 1 \mathrm{~s}$ core-level spectrum, as seen in Figure 2a. Considering the relationship between electronegativity and binding energy, the peaks at 284.5, 283.7, 285.6, and $287.9 \mathrm{eV}$, labeled as $\mathrm{C} 1, \mathrm{C} 2, \mathrm{C} 3$, and $\mathrm{C} 4$, were assigned to $-\mathrm{CH}\left(\mathrm{CH}_{3}\right)_{2},-\mathrm{CH}_{2},-\mathrm{CH}-\mathrm{NH}_{2}$, and a deprotonated carboxyl carbon (-COO-), respectively. Figure $2 \mathrm{~d}$ displays the deconvoluted spectrum of the $\mathrm{C} 1 \mathrm{~s}$ core-level region after adsorption of $\sim 0.20 \mathrm{ML}$ Tyr on the $\mathrm{Cu}(110)$ surface. As seen, we observed the presence of five chemically distinct types of carbon on the $\mathrm{Cu}(110)$ surface. The strongest peak appeared at $284.9 \mathrm{eV}$, assigned to the aromatic ring of Tyr, labeled $\mathrm{C} 5\left(-\mathrm{C}_{6} \mathrm{H}_{5}-\right)$. Four other peaks were assigned corresponding to $\mathrm{CH}_{2}-(283.7 \mathrm{eV}: \mathrm{C} 6), \mathrm{C}_{-} \mathrm{NH}_{2}(285.3 \mathrm{eV}: \mathrm{C} 7), \mathrm{COO}-(288.4 \mathrm{eV}: \mathrm{C} 8)$, and C-OH (287.1 eV: C9), respectively. These observations suggested the presence of an electronically neutral (C3 and N1) amine group for Leu but a positively charged (C7 and N2) form of the amine for Tyr [19].

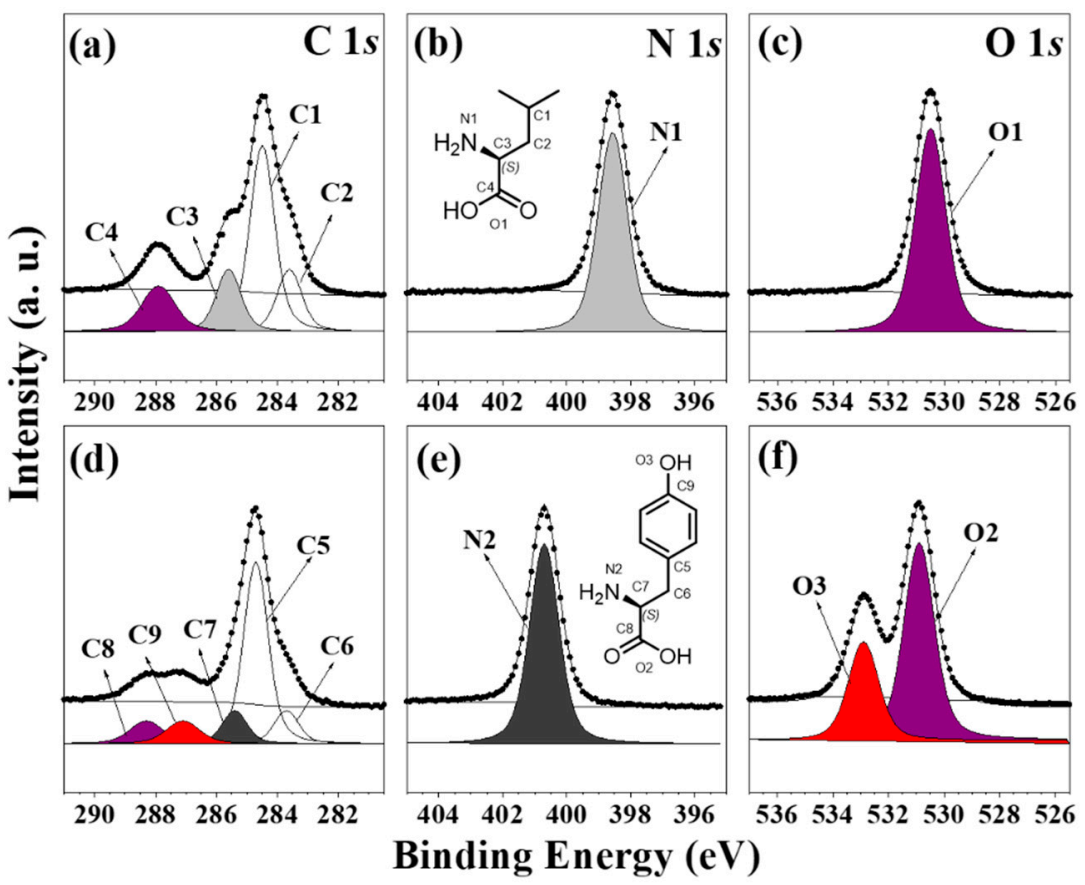

Figure 2. (a-f) C 1s, N 1s, and O 1s core-level spectra for Leu (a,b, and $\mathbf{c})$ and for Tyr (d,e, and f), in each case on the $\mathrm{Cu}(110)$ surface with an $\sim 0.20 \mathrm{ML}$ deposition: the dots indicate experimental values, and the solid lines represent the results of peak fittings.

Concurrently, the changes in the $\mathrm{N} 1$ s and $\mathrm{O} 1$ s core-level spectra at the $\sim 0.20 \mathrm{ML}$ level of coverage were determined using the same methods for the two amino acids adsorbed on the $\mathrm{Cu}(110)$ surface. The $\mathrm{N} 1 \mathrm{~s}$ core-level spectrum of $\sim 0.2 \mathrm{ML}$ Leu on the $\mathrm{Cu}(110)$ surface in Figure $2 \mathrm{~b}$ showed a single peak at $398.5 \mathrm{eV}$ (marked as N1). Considering the binding energy, $\mathrm{N} 1$ was assigned to the neutral $\mathrm{N}$ atom in 
the Leu molecule [20-22]. The N 1s core-level spectrum obtained for $\sim 0.20 \mathrm{ML}$ Tyr adsorbed on the $\mathrm{Cu}(110)$ surface, as in Figure 2e, also showed a single peak, but at $400.5 \mathrm{eV}$. This result was indicative of the $\mathrm{N}$-dative bonding structure for the adsorbed Tyr.

Finally, the $\mathrm{O} 1 \mathrm{~s}$ peaks of the adsorbed Leu and Tyr molecules were determined and compared. Figure $2 \mathrm{c}$ shows the $\mathrm{O} 1 \mathrm{~s}$ core-level spectrum obtained after deposition of $\sim 0.20 \mathrm{ML}$ Leu on the $\mathrm{Cu}(110)$ surface. Both oxygen atoms of Leu adsorbed equivalently on the $\mathrm{Cu}(110)$ surface, as indicated by the $\mathrm{O} 1 \mathrm{~s}$ spectrum showing a single peak (marked as $\mathrm{O} 1$ at $530.5 \mathrm{eV}$ ). This equivalent adsorption was apparently a result of the $\mathrm{Cu}(110)$ surface having an equivalent dimer. The $\mathrm{O} 1 \mathrm{~s}$ core-level spectrum of Tyr on the $\mathrm{Cu}(110)$ surface, shown in Figure 2f, was found to display two oxygen peaks: one peak (marked as $\mathrm{O} 2$ at $530.9 \mathrm{eV}$ ) being similar to that for Leu and corresponding to the two deprotonated carboxyl oxygens adsorbed equivalently on the $\mathrm{Cu}(110)$ surface and the other peak (marked as $\mathrm{O} 3$ at $532.9 \mathrm{eV}$ ) being the phenol oxygen. In previous experiments of Leu adsorbed on a $\mathrm{Ge}(100)$ surface, the $\mathrm{O} 1$ s peaks were divided into two components, $\mathrm{O}-\mathrm{Ge}$ and $-\mathrm{C}=\mathrm{O}$, which could be done because of the chemical inequivalence of the oxygen atoms in such Leu resulting from the zwitterionic character of the Ge(100) surface $[13,23]$. The analyses of the C 1s, N 1s, and O 1s core-level high-resolution photoelectron spectra taken together revealed that, at low coverage, the Leu adsorbed on the $\mathrm{Cu}(110)$ surface adopted the $\mathrm{O}-\mathrm{H}$ dissociation bonded structure, whereas the Tyr system showed the $\mathrm{O}-\mathrm{H}$ dissociated-N dative bonded structure.

DFT calculations were also performed to determine the most stable adsorption structural features of Leu and Tyr on the $\mathrm{Cu}(110)$ and their corresponding adsorption energies. The same calculation procedure was employed for both amino acid molecules. Figure 3 shows these two DFT-optimized structural features from the front and top, with respect to calculating the adsorption energies. As shown in Figure 3, the $\mathrm{O}-\mathrm{H}$ dissociation bonded structure, containing a neutral N, was calculated to be the most stable adsorption structure for Leu on the $\mathrm{Cu}(110)$ surface, with an Eads of $-45.23 \mathrm{kcal} / \mathrm{mol}$, rather than the O-H dissociated-N dative bonded structure with Eads of $-19.86 \mathrm{kcal} / \mathrm{mol}$, as seen Figure $3 \mathrm{a}, \mathrm{c}$. Taking into account the stability of the structure of Leu adsorbed on the $\mathrm{Cu}(110)$ surface, as predicted using the DFT calculations, together with the experimental HRPES results, the $\mathrm{O}-\mathrm{H}$ dissociation bonded structure was found to be most stable for Leu in the low-coverage regime. Using the same method, the adsorption structure of Tyr on the $\mathrm{Cu}(110)$ surface was also calculated.

In contrast to the case of Leu, the $\mathrm{O}-\mathrm{H}$ dissociated-N dative bonded structure, containing a charged $\mathrm{N}$ and calculated using DFT, was found to be the more stable structure for Tyr on $\mathrm{Cu}(110)$, with an Eads of $-38.76 \mathrm{kcal} / \mathrm{mol}$, rather than the $\mathrm{O}-\mathrm{H}$ dissociation bonded structure, with an Eads of $-24.34 \mathrm{kcal} / \mathrm{mol}$, as seen Figure $3 \mathrm{~b}$,d. These results clearly show the $\mathrm{O}-\mathrm{H}$ dissociated-N dative bonded structure to be preferred for the adsorption structure of Tyr. Additionally, clear illustration of the difference for the $\mathrm{O}-\mathrm{H}$ dissociation bonded structure of Leucine versus the $\mathrm{O}-\mathrm{H}$ dissociated $-\mathrm{N}$ dative bonded structure with a charged $\mathrm{N}$ for Tyrosine was shown in Figure $3 \mathrm{e}$. 

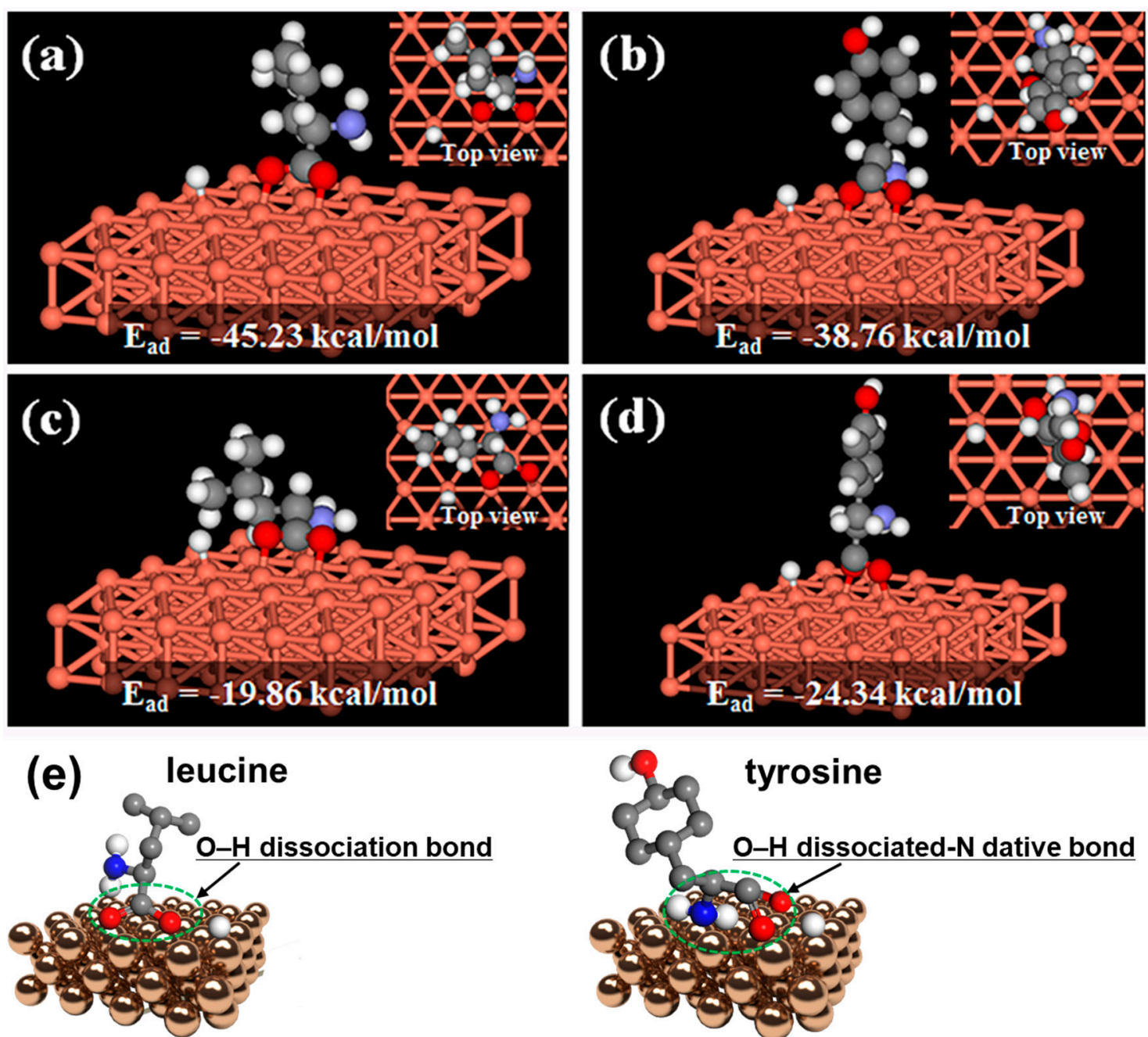

$\mathrm{Cu}(110)$

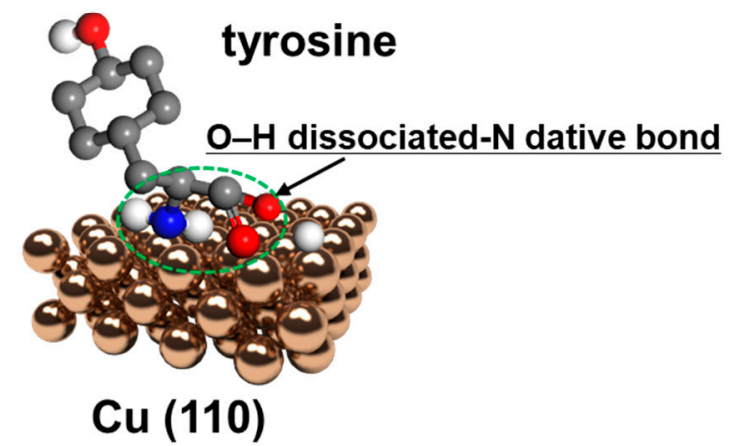

Figure 3. Density functional theory (DFT) calculations and molecular adsorption features for (a) the $\mathrm{O}-\mathrm{H}$ dissociation bonded structure and (c) the $\mathrm{O}-\mathrm{H}$ dissociated-N dative bonded structure of Leu and for $(\mathbf{b})$ the $\mathrm{O}-\mathrm{H}$ dissociated-N dative bonded structure and (d) the $\mathrm{O}-\mathrm{H}$ dissociation bonded structure of Tyr on the $\mathrm{Cu}(110)$ surface. (e) Illustration of the difference for $\mathrm{O}-\mathrm{H}$ dissociation bonded structure of Leucine versus the $\mathrm{O}-\mathrm{H}$ dissociated $-\mathrm{N}$ dative bonded structure with a charged $\mathrm{N}$ for Tyrosine.

\section{Conclusions}

The structures of leucine and tyrosine adsorbed at a low coverage on a $\mathrm{Cu}(110)$ surface were determined using RAIRS, HRPES, and DFT. The results revealed that the amine and carboxyl groups of Leu and Tyr concurrently participated in this adsorption. It is concluded that the $\mathrm{O}-\mathrm{H}$ dissociation bonded structure is the most favorable structure for Leu initially adsorbed on a $\mathrm{Cu}(110)$ surface, whereas the $\mathrm{O}-\mathrm{H}$ dissociated-N dative bonded structure is the most favorable structure for an adsorbed Tyr. As we observed, low coverage of the adsorption ssceme tructure of amino acids on a $\mathrm{Cu}(110)$ surface can support the conventional chemical reactions be applied in recently emerging biomedical applications. Conclusively, we confirm that our approach of a comparative study of initial adsorption structures for amino acids will be extended by practical industrial applications using amino acids adsorptions, such as bio-related science and bio-engineering.

Author Contributions: H.S.K. and H.L. performed the experiments; H.S.K. and H.L. analyzed the data and wrote the paper. All authors have read and agreed to the published version of the manuscript. 
Funding: This research was supported by the National Research Foundation of Korea (NRF) funded by the Korean government (MSIP) (No. 2017R1A2A2A05001140).

Acknowledgments: We thank Y. R. Son for help in drawing the graphical abstract.

Conflicts of Interest: The authors declare no conflict of interest.

\section{References}

1. Bent, S.F. Organic Functionalization of Group IV Semiconductor Surfaces: Principles, Examples, Applications, and Prospects. Surf. Sci. 2002, 500, 879-903. [CrossRef]

2. Loscutoff, P.W.; Bent, S.F. Reactivity of the Germanium Surface: Chemical Passivation and Functionalization. Annu. Rev. Phys. Chem. 2006, 57, 467-495. [CrossRef] [PubMed]

3. Hamers, R.J. Formation and Characterization of Organic Monolayers on Semiconductor Surfaces. Annu. Rev. Anal. Chem. 2008, 1, 707-736. [CrossRef] [PubMed]

4. Whaley, S.R.; English, D.S.; Hu, E.L.; Barbara, P.F.; Belcher, A.M. Selection of peptides with semiconductor binding specificity for directed nanocrystal assembly. Nature 2000, 405, 665-668. [CrossRef]

5. Goede, K.; Busch, P.; Grundmann, M. Binding Specificity of a Peptide on Semiconductor Surfaces. Nano Lett. 2004, 4, 2115-2120. [CrossRef]

6. Schiffrin, A.; Riemann, A.; Auwarter, W.; Pennec, Y.; Iber-Bargioni, A.; Cvetko, D.; Cossaro, A.; Morgante, A.; Barth, J.V. Zwitterionic self-assembly of L-methionine nanogratings on the Ag(111) surface. Proc. Natl. Acad. Sci. USA 2007, 104, 5279-5284. [CrossRef]

7. Leftwich, T.; Teplyakov, A.V. Chemical manipulation of multifunctional hydrocarbons on silicon surfaces. Surf. Sci. Rep. 2007, 63, 1-71. [CrossRef]

8. Barlow, S.M.; Raval, R. Complex organic molecules at metal surfaces: Bonding, organisation and chirality. Surf. Sci. Rep. 2003, 50, 201-341. [CrossRef]

9. Crivillers, N.; Osella, S.; Van Dyck, C.; Lazzerini, G.M.; Cornil, D.; Liscio, A.; Di Stasio, F.; Mian, S.; Fenwick, O.; Reinders, F.; et al. Large Work Function Shift of Gold Induced by a Novel Perfluorinated Azobenzene-Based Self-Assembled Monolayer. Adv. Mater. 2013, 25, 432-436. [CrossRef]

10. Lee, H.; Youn, Y.-S.; Kim, S. Coverage Dependence of the Adsorption Structure of Alanine on Ge(100). Langmuir 2009, 25, 12574-12577. [CrossRef]

11. Yang, S.; Kim, Y.; Park, S.; Kim, K.-j.; Lee, H. Coverage Dependent Variation of Adsorption Configurations of Methionine on Ge(100). Chem. Asian J. 2011, 6, 2362-2367. [CrossRef] [PubMed]

12. Lim, H.; Yang, S.; Lee, M.; Kim, S.; Lee, H. Variation of Adsorption Geometries by the Influence of Nucleophilicity among p-CPA, p-TPA, and p-NPA on Ge(100) Surfaces. Chem. Phys. Lett. 2013, 578, 162-166. [CrossRef]

13. Yang, S.; Lim, H.; Park, E.H.; Kim, Y.; Min, Y.H.; Lee, H.-S.; Kim, S.; Lee, H. Comparison and Contrast Analysis of Adsorption Geometries of Phenylalanine versus Tyrosine on Ge(100): The Effect of Nucleophilic Group on the Surface. J. Phys. Chem. C 2012, 116, 25840-25845. [CrossRef]

14. Antonio, L.; Barbosa, M.M.; Sautet, P. Stability of Chiral Domains Produced by Adsorption of Tartaric Acid Isomers on the $\mathrm{Cu}(110)$ Surface: A Periodic Density Functional Theory Study. J. Am. Chem. Soc. 2001, 123, 6639-6648.

15. Schreier, F. The Voigt and complex error function: A comparison of computational methods. J. Quant. Spectros. Radiat. Transf. 1992, 48, 743-762. [CrossRef]

16. Lee, C.; Yang, W.; Parr, R.G. Development of the Colle-Salvetti correlation-energy formula into a functional of the electron density. Phys. Rev. B 1988, 37, 785. [CrossRef]

17. Hay, P.J.; Wadt, W.R. Ab initio effective core potentials for molecular calculations. Potentials for K to Au including the outermost core orbitals. J. Chem. Phys. 1985, 82, 299. [CrossRef]

18. Williams, J.; Haq, S.; Raval, R. The bonding and orientation of the amino acid L-alanine on Cu (110) determined by RAIRS. Surf. Sci. 1996, 368, 303-309. [CrossRef]

19. Park, S.; Yang, S.; Shin, N.; Lee, E.; Lee, H. Adsorption Configuration for Cysteine on Ge(100): Coverage Dependent Surface Reorientation. J. Phys. Chem. C 2010, 114, 14528-14531. [CrossRef]

20. Yang, S.; Kim, Y.; Park, S.; Lim, H.; Lee, H. Adsorption Configuration of Serine on Ge(100): Competition between the Hydroxymethyl and Carboxyl groups of Serine During the Adsorption Reaction. J. Phys. Chem. C 2011, 115, 9131-9135. [CrossRef] 
21. Guo, H.; Chrysostomou, D.; FloIrs, J.; Zaera, F. Effect of Coadsorbed Oxygen on the Chemistry of Ammonia over Ni(110) Single-Crystal Surfaces. J. Phys. Chem. B 2003, 107, 502-511. [CrossRef]

22. Bernardo, C.G.P.M.; Gomes, J.A.N.F. The adsorption of ethylene on the (110) surfaces of copper, silver and platinum: A DFT study. J. Mol. Struct. 2002, 582, 159-169. [CrossRef]

23. Yang, S.; Park, Y.; Kim, J.W.; Lee, H. Variation of Coverage-Dependent Attachment of Multifunctional Groups in Alanine and Leucine to the Ge(100)-2x1 Surface: Bonding Configuration and Adsorption Stability. J. Phys. Chem. C 2011, 115, 19287-19292. [CrossRef]

(C) 2020 by the authors. Licensee MDPI, Basel, Switzerland. This article is an open access article distributed under the terms and conditions of the Creative Commons Attribution (CC BY) license (http://creativecommons.org/licenses/by/4.0/). 